\title{
Enhancing Service-Oriented Behaviors in an Asian Business Context: Lessons From a Pakistani Bank
}

\author{
Dr. Sebastian Fuchs \\ Senior Manager, People Advisory Services, Ernst \& Young Middle East \\ 25th Floor, Nation Tower 2 - Corniche, Abu Dhabi, United Arab Emirates \\ E-mail: sebastian.fuchs@ae.ey.com
}

\begin{abstract}
Dr. Rea Prouska (Corresponding author)
Associate Professor of Human Resource Management, London South Bank University 103 Borough Road, London, SE1 0AA, United Kingdom

E-mail: prouskar@1sbu.ac.uk
\end{abstract}

Prof. Alexandros Psychogios

Professor of International Human Resource Management, Birmingham City University The Curzon Building, 4 Cardigan Street, Birmingham, B4 7BD, United Kingdom E-mail: alexandros.psychogios@bcu.ac.uk

Received: February 11, 2018 Accepted: October 10, 2018 Published: October 12, 2018 doi: $10.5296 /$ hrr.v2i1.12652 URL: https://doi.org/10.5296/hrr.v2i1.12652

\begin{abstract}
This article examines how service organizations can enhance employees' customer orientation, often exhibited through the display of service-oriented citizenship behaviors. The study, in this respect, quantitatively analyses the relationships between organizational distributive justice, leader-member exchange (LMX), and team-member exchange (TMX) on customer orientation. Data were gathered through a survey of 658 middle managers working in a Pakistani bank and were analyzed via full structural equation modelling. The findings reveal that organizational distributive justice, LMX, and TMX are key predictors of customer
\end{abstract}


orientation. Specifically, the analysis suggests that the relationships between organizational distributive justice and LMX with customer orientation are mediated partially and fully, respectively, by TMX. Simultaneously, TMX partially mediates the relationship between organizational tenure and customer orientation. Our study contributes to both theory and practice of service organization functioning by signifying the importance of the organization's fair distribution of rewards as well as it's leader's and co-worker's behaviors in affecting organizationally desired employee behaviors and thereby, arguably, enabling positive organizational outcomes. Service organizations can, based on our findings, create a culture of service excellence by placing emphasis on specific elements at the organizational, leadership, and team level.

Keywords: Customer orientation, Leader-member exchange, Team-member exchange, Organizational distributive justice, Service-oriented citizenship behavior, Service organization

\section{Introduction}

A service-oriented organizational culture has been explored for its importance in achieving competitive advantage, business growth, profitability, financial performance, and success through customer satisfaction and loyalty (Homburg, Hoyer, \& Fassnacht, 2002). In such a culture, employee behaviors that go beyond addressing the formal job requirements have been positively associated with higher customer satisfaction and overall organizational productivity (Podsakoff, Whiting, Podsakoff, \& Blume, 2009). It has also been argued that a lack of understanding and inability to create a service-oriented culture can inhibit long-term organizational performance (Lytle, Hom, \& Mokwa, 1998). It is, therefore, critical that organizations are able to understand how such a culture can be built and fostered. Research has suggested that SOCBs are critical for the delivery of superior customer service (Appelbaum et al., 2003; Shetach \& Marcus, 2015).

The question that emerges, based on this logic, is how organizations can develop a service-oriented culture. Lytle et al. (1998, p. 459) argued that it can be developed through the "organization-wide embracement of a basic set of relatively enduring organizational policies, practices, and procedures intended to support and reward service-giving behaviors that create and deliver service excellence". A service culture of excellence can be achieved through ten fundamental elements according to Lytle and Timmerman (2006); service vision, servant leadership, customer treatment, employee empowerment, service training, service rewards, service technology, service failure prevention, service failure/recovery, and service standards communication. These elements are under the direct influence of middle and senior managers in service organizations. Therefore, management plays a vital role in leading and managing service orientation as it is responsible for creating and communicating a service vision, empowering employees, training and rewarding staff for high quality service, and creating management control systems for preventing and recovering from service failures (Menguc \& Auh, 2008). Management controls the development and implementation of such policies, practices, and procedures, and thus, is ultimately responsible for creating a service culture powerful enough to affect the quality of the overall service delivery. 
A key element in creating service-oriented cultures is, importantly, employee SOCBs (Auh, Menguc, \& Jung, 2014; Bettencourt, Gwinner, \& Meuter, 2001; Castro, Armario, \& Ruiz, 2004; Jain, Malhotra, \& Guan, 2012), such as customer orientation (Lanjananda \& Patterson, 2009). Customer orientation means putting customers first, focusing on the needs and wants of customers, and placing them at the center of an organization's strategy (Cross, Brashear, Rigdon, \& Bellenger, 2007; Maas \& Graf, 2004).

The purpose of this paper is to explore the notion of a service-oriented organizational culture and how this can be fostered through SOCBs, namely customer orientation. In particular, our research explores the links between organizational distributive justice, leader-member exchange (LMX), team-member exchange (TMX), and customer orientation, as these are closely associated with the notion of a service-oriented culture (Bettencourt et al., 2001; DeConinck \& Stilwell, 2004; Chou \& Lopez-Rodriguez, 2013; Colquitt, Conlon, Wesson, Porter, \& Ng, 2001; Kwan, Yim, \& Zhou, 2015; Lytle \& Timmerman, 2006; Mahajan \& Benson, 2013; Wesche \& Teichmann, 2016).

The paper is organized in five parts. The first part presents the theoretical framework and hypotheses. The second part discusses the methods used for data collection. The third and fourth parts constitute the results and discussion. The fifth part concludes the paper by summarizing the key contributions of the research and presenting avenues for future research.

\section{Literature Review and Hypotheses Development}

\subsection{Organizational Distributive Justice}

Organizational distributive justice is concerned with an individual's perception of whether $\mathrm{s} /$ he receives fair treatment by the organization not only in terms of whether rewards are impartially distributed, but also in terms of punishment (Chou \& Lopez-Rodriguez, 2013). Different scholars have highlighted the positive effects of organizational distributive justice on employee commitment, employee satisfaction with rewards, job attitudes, work quality, job satisfaction, cooperation with co-workers, and labor turnovers, among others (DeConinck \& Stilwell, 2004; Hornung, Glaser, \& Rouseau, 2010). Low levels of organizational distributive justice, on the other hand, have been associated with opportunistic employee behaviors against the interest of the organization (Mahajan \& Benson, 2013).

Employees' justice perceptions are rooted in social exchanges (Cardona, Lawrence, \& Bentler, 2004) as employees who perceive the distribution of rewards and resources to be fair and equitable respond positively by being more cognitively, physically, and emotionally engaged in the workplace (Biswas, Varma, \& Ramaswami, 2013) leading, among other things, to innovative behaviors at work (Pundt, Martins, \& Nerdinger, 2010). We, therefore, hypothesize that if organizations want to become customer oriented by embracing organizational policies, practices, and procedures intended to support and reward service-giving behaviors that create and deliver service excellence (Lytle et al., 1998), they require a high level of cognitive, physical, and emotional engagement by employees. Organizational distributive justice may be a critical mechanism in creating such engagement. On the basis of this logic, we hypothesize the following: 


\section{MInstitute ${ }^{\text {Mink }}$}

2.1.1 Hypothesis 1: Organizational Distributive Justice Is Positively Associated With Customer Orientation

\subsubsection{Leader-member Exchange (LMX)}

Leaders in organizations form a variety of exchange relationships with their subordinates. The quality of this relationship is based on the degree of support (Paillé, 2009; Steffens, Haslam, Kerschreiter, Schuh, \& van Dick, 2014) and exchange of valued resources between these two parties and can lead to either low-quality leader-member relations characterized by mere contractual exchanges, or to high-quality relations supported through social exchange mechanisms. This latter type of relationship typically extends beyond the mere contractual requirements often evident in a work context (Brunetto, Farr-Wharton, \& Shacklock Brunetto, 2010). Because of this, LMX has been examined as a factor which can affect organizational identification. Employees in high LMX relationships are more likely to develop a personalized customer orientation and to have access to supervisor support to help them with customer interactions (Tangirala, Green, \& Ramanujam, 2007). The importance of leaders and of leadership style in creating SOCBs and customer orientation has widely been discussed in the literature (Carter, Mossholder, Field, \& Armenakis, 2014; Chiaburu, Lorinkova \& Van Dyne, 2013; González \& Garazo, 2006; Menguc \& Auh, 2008; Martin \& Bush, 2003), in particular how a transformational leadership style can enable customer orientation (MacKenzie, Podsakoff \& Rich, 2001; Harris \& Ogbanna, 2001). A positive relationship between LMX and customer orientation has been established (Paparoidamis \& Guenzi, 2009), as well as a strong LMX-organizational identification relationship and a significant LMX-customer orientation relationship (Farrell \& Oczkowski, 2012). Accordingly, we hypothesize the following:

2.1.2 Hypothesis 2: Leader-member Exchange Is Positively Associated With Customer Orientation

\subsubsection{Team-member Exchange (TMX)}

TMX relates to the reciprocity between an individual with his/her team members with respect to contribution of ideas, feedback, and assistance, in return for information, help, and recognition (Seers, 1989; Seers, Petty, \& Cashman, 1995). Liu, Loi and Lam (2011) suggested that high-quality TMX enables team members to receive important psychological and socio-emotional resources. They further discuss that this can facilitate organizational identification with positive effects on employee in-role and organizational citizenship behavior (OCB), whereas low-quality TMX would only have a minimal effect on the team member's willingness to share information with peers and provide assistance and recognition to them, therefore limiting exchanges to the standard requirement of job completion. To be more precise, OCB tends to be excluded from formal organizational expectations such as job descriptions and relates to discretionary individual behaviors that are not explicitly recognized by the formal reward system (Jiao, Richards, \& Hackett, 2013).

Closely related to this concept is the notion of SOCB, which refers to customer focused discretionary behaviors that extend beyond the employees' formal role requirements when servicing customers (Chou \& Lopez-Rodriguez, 2013). SOCB can lead to increased employee loyalty and participation and overall higher-quality service delivery (Bettencourt et 
al., 2001). The fact that the desired outcome of SOCB is higher-quality service delivery suggests that SOCB incorporates the concept of customer orientation which focuses on customer loyalty and satisfaction (Lytle \& Timmerman, 2006; Homburg et al., 2002; Lytle et al., 1998).

When considering the relationship between organizational justice and SOCB, Chou and Lopez-Rodriguez (2013) argued that from a social exchange perspective, one can expect that service employees are likely to engage in service-related discretionary behaviors as an exchange for fair treatment received by the organization, and that service employees' perceptions of fair treatment are expected to have an important impact on their SOCB. As it was argued above, SOCB is similar to customer orientation, and thus, Chou and Lopez-Rodriguez's (2013) arguments can be extended to include a positive link between organizational justice and customer orientation.

Further to this argument, Ohana (2012) found that group commitment moderated the relationship between perceived organizational support (POS) and job satisfaction and that this interaction effect, in turn, mediates the distributive justice-job satisfaction relationship. Additional literature on POS (Byrne \& Hochwarter, 2008; Rhoades \& Eisenberger, 2002) presents the view that employees form beliefs concerning the extent to which the organization values their contributions and cares about their well-being and suggest that employee behaviors, such as service orientation towards customers, can be affected by such beliefs. One aspect of POS relates to perceived co-worker support which refers to the degree to which employees perceive that their co-workers care about their well-being, respect their contributions to the organization, help them acquire new skills and knowledge, and support them in times of organizational change (Fuchs \& Prouska, 2014). This is related to the notion of TMX which refers to reciprocity between a member and his/her team which in turn may facilitate organizational identification and has positive effects on OCB and SOCB (Liu et al., 2011). Furthermore, one important aspect of POS is co-worker support which is closely linked to TMX (Seers et al., 1995), and because POS can be influential in affecting employee behaviors (Byrne \& Hochwarter, 2008) such as customer orientation, we hypothesize the following:

\subsubsection{Hypothesis 3: Team-member Exchange Mediates the Relationship Between} Organizational Distributive Justice and Customer Orientation

The role of leadership in creating high-quality LMX that extends beyond the mere contractual requirements has been widely discussed in the literature (Carter et al., 2014; Kahrobaei \& Mortazavi, 2016; Menguc \& Auh, 2008; Martin \& Bush, 2003; MacKenzie et al., 2001; Harris \& Ogbanna, 2001). Oczkowski (2012) and Paparoidamis and Guenzi (2009), for instance, have established a positive relationship between LMX and customer orientation. Leadership styles fostering organizational support as discussed in the POS literature (Byrne \& Hochwarter, 2008; Rhoades \& Eisenberger, 2002) can be strong enough to influence TMX and enable individuals to exhibit citizenship behaviors. In more detail, LMX is linked to citizenship behaviors and typically high-quality LMX is characterized by high levels of trust, interaction, support, and formal/informal rewards, including an exchange of material and non-material goods that extend beyond what the formal job description specifies (Ilies, Nahrgang, \& Morgeson, 2007). In order to reciprocate high LMX relationships, subordinates 
will go beyond their specified role and engage in citizenship behaviors to maintain an equitable exchange (Kuvaas \& Dysvik, 2010). Due to the established positive relationship between LMX and customer orientation (Oczkowski, 2012; Paparoidamis \& Guenzi, 2009) and given that leadership styles in LMX can affect TMX (Byrne \& Hochwarter, 2008), and further may in turn affect customer orientation, we hypothesize the following:

2.1.4 Hypothesis 4: Team-member Exchange Mediates the Relationship Between Leader-Member Exchange and Customer Orientation

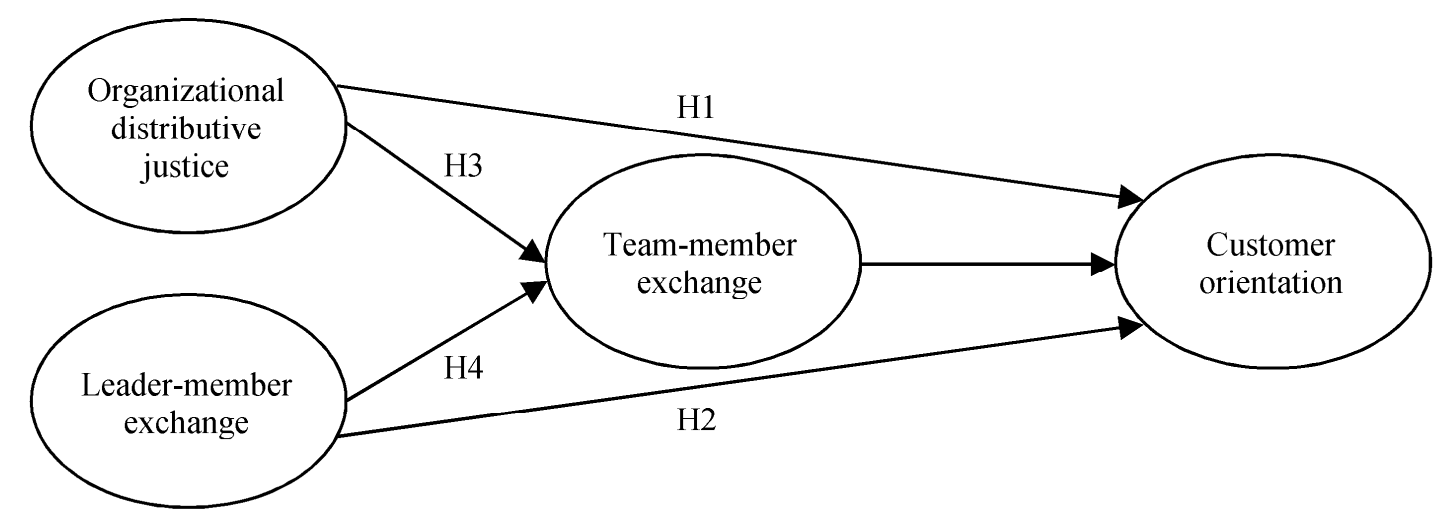

Figure 1. The hypothesized model

Note: $\mathrm{H} 1=$ Hypothesis $1, \mathrm{H} 2=$ Hypothesis 2, H3=Hypothesis 3, H4=Hypothesis 4.

\section{Method}

\subsection{Context}

The study followed a quantitative approach in order to test the above hypotheses. The investigation occurred in one of the largest financial institutions in Pakistan, which has operations across the entire country. Pakistan is an emerging market that has undergone and continues to undergo significant structural transformations based on liberal market reforms that attempt to develop a promising economy despite its still volatile and weak business system (Jormanainen \& Koveshnikov, 2012). The banking sector in Pakistan is on the whole under-researched, even though more attention has recently been drawn on exploring various issues in conventional and Islamic banking in emerging markets (Rammal \& Parker, 2012). The banking sector is one of the fastest growing service sectors in Pakistan, and the with this associated increase in competition poses critical pressures to organizations to become more customer-focused by fostering a customer-oriented culture (Qayyum, Sukirno, \& Mahmood, 2011). It is, therefore, important to explore how SOCBs, such as customer orientation, can be developed within this context, since this may provide useful insights for banks operating in Pakistan and potentially in other emerging economies.

\subsection{Sample}

The organization employs more than 80,000 people in Pakistan. Our survey focused on middle managers due to their important role in changing the culture of an organization (Psychogios, 


\section{MInstitute ${ }^{\text {Mink }}$}

Alexandris, \& Onofrei, 2008) and creating a strategic orientation towards service-oriented culture (Balogun \& Johnson, 2004; Huy, 2011). For the purpose of this study, we adopted a broad definition of middle managers suggested by Dopson, Risk and Stewart (1992), including all those managers just below the group of senior managers (CEOs, CFOs, etc.). In particular, the whole population of these managers that were approached included 660 individuals holding a regional head position in one of the functional areas in the bank; audit, financial control, commercial/consumer/wholesale banking, operations, treasury and foreign exchange investment, special asset management, Islamic banking, strategic planning and capital markets, risk management, business development, compliance, human resources, and IT. In total, 658 responses were received, representing a $99.7 \%$ response rate. Such a high response rate is not untypical for quantitative studies conducted in high power distance cultures such as Pakistan (House, Hanges, Javidan, Dorfman \& Gupta, 2004), as filling in a survey distributed via top management may be something that is seen as a duty rather than a voluntary activity. Each respondent received an email introducing him/her to the purpose of this research and an invitation to fill in an electronic version of the questionnaire.

The questionnaire was written in English and Urdu, so that all participants could understand and fill in the survey. A one-pager accompanied the questionnaire signed by the President and the Group Head HR to ensure a high response rate. From the 658 respondents $88 \%$ were male. In terms of their age group, $14 \%$ were $20-30$ years old, 30\% 31-40 years, 19\% 41-50 years, and 37\% were 51 years old or older. Most respondents $(31 \%)$ had a long length of service at the company of 30 or more years, $15 \%$ of $21-30$ years, $12 \%$ of $11-20$ years, $9 \%$ of $4-10$ years, $19 \%$ of $1-3$ years, and $14 \%$ of less than 1 year. The majority of respondents $(54 \%)$ were holders of a postgraduate degrees (M.A., M.B.A., M.Sc., etc.), 37\% of an undergraduate degree (e.g. B.A., B.Sc., etc.), and $0.3 \%$ were holders of a Ph.D.

\subsection{Measures}

All study variables were measured on a five-point Likert-type scale asking for respondents' agreement, disagreement, or indifference $(1=$ agree, $2=$ somewhat agree, $3=$ neutral $4=$ somewhat disagree, $5=$ disagree). All scores were reversed prior to the analyses so that higher values reflect stronger agreement and lower values weaker agreement with the questionnaire items. Organizational distributive justice was measured with the scale suggested by Byrne and Cropanzano's (2000) scale. Sample items include "My compensation as compared to the industry average (top 4 local banks) is fair and equitable" and "I believe that my workplace rewards are given fairly". $L M X$ was measured with the scale proposed by Wang, Law and Chen (2008). The scale includes items such as "My manager/supervisor is available to me when I have questions or need help" and "My manager/supervisor effectively resolves employee problems and issues". The TMX scale was adopted form Seers' (1989) work. Sample items are "Employees at [the organization's name] regularly share and exchange ideas" and "In [the organization's name], teamwork is encouraged and recognized". Customer orientation was measured with items adapted from the SOCO scale developed by Saxe and Weitz (1982), such as "I try to help customers achieve their goals", "I try to get customers to discuss their needs with me", "I try to figure out what a customer's needs are", and "I try to find out what kind of product would be most helpful to a customer". 


\subsection{Data Analysis}

Our analysis consists of two key elements based on DeVellis's (2003) and Long's (1983) recommendations and is performed in LISREL 8.80 (SSI, Scientific Software International, Lincolnwood, IL). Firstly, we tested our measurement scales using confirmatory factor analysis to identify their psychometric properties. After this, we conducted independence and the Harman (1976) test to determine the independence and empirical distinctiveness of our variables. Due to violations of non-normality assumptions associated with five-point Likert-type questionnaire items, the data is treated as ordinal, and polychoric correlation matrices with associated asymptotic covariance matrices are created as input into the analysis (Jöreskog, 2005). The independence and Harman (1976) tests involve a number of steps. Firstly, all items of each study variable are loaded onto their respective latent construct in combination with the items of another latent construct (e.g. organizational distributive justice and LMX). Secondly, all of these items are loaded onto a single latent factor before their fit to the data is compared with the two-factor model. If the two-factor model fits the data better than the one-factor model, both constructs are empirically distinct from each other. Thirdly, for the Harman (1976) test, all items are loaded onto their respective latent construct for all four study variables, and subsequently onto a single factor. A data fit comparison of both models then indicates the distinctiveness of all study variables. In line with the recommendations put forward by Jöreskog (2005) and Satorra and Bentler (2010), we also performed the Satorra-Bentler (2010) scaled chi square difference test (SB $\chi 2$ difference) to determine the statistical difference of our measurement scales.

Secondly, when testing our structural models, we treated the multi-item constructs as continuous data and use covariance matrices in line with Jöreskog's (2005) recommended approach for full structural equation modelling. Further, and in line with the analytic convention for mediation analysis presented by Baron and Kenny (1986) and Kelloway (1998), we firstly tested a fully mediated version of our structural model as supported by Hypotheses 3 and 4, then a partially mediated version of the model, and finally a non-mediated version of the model. The model with the best fit to the data subsequently constituted our final and supported structural model. We considered four key control variables (age, gender, organizational tenure, and educational level) as they have been linked to a number of our study variables in similar research (e.g. Halstead, Jones, Lesseig, \& Smythe, 2008).

To determine the adequacy of our measurement and structural models, we adhere to a number of fit indices commonly applied to this type of analysis. Specifically, and in line with $\mathrm{Hu}$ and Bentler (1999) and Jöreskog (2005), the chi square $\left(\chi^{2}\right)$ statistic used in our study is the SB $\chi^{2}$ as it adjusts for non-normality with ordinal data in confirmatory modelling (i.e. the confirmatory factor analyses). For our structural models (and the respective difference tests) which treat the data as continuous, however, we have used the normal theory $\chi^{2}$ as suggested by Jöreskog (2005). Regarding the $\chi 2$ degrees of freedom (df) ratio, we rely on Bollen (1989) and Kelloway's (1998) recommendation and consider a ratio below two as a good fitting model, a ratio between two and three as an acceptable fit, and a ratio between three and five as approaching an acceptable level of fit. For the standardized root mean square residual (SRMR) and the root mean square error of approximation (RMSEA), we have used a cut-off 


\section{Mll Macrothink}

Human Resource Research

ISSN 1948-5441

2018, Vol. 2, No. 1

of 0.05 for good fitting models, a cut-off between 0.05 and 0.08 for acceptably fitting models, and a cut-off between 0.08 and 0.10 for models that approach an acceptable fit (Hu \& Bentler, 1999; Steiger, 2000). Additionally, we have presented the comparative fit index (CFI) and the goodness of fit index (GFI). For these indices, and in line with Bollen (1989), we have treated values between 1.00 and 0.95 as indicators of good-fitting models, values between 0.95 and 0.90 as indicators of satisfactorily-fitting models, and values below 0.90 as indicators of models that approach acceptable levels fit. The expected cross-validation index (ECVI) is used to determine the badness of fit, with higher values indicating a weaker fit to the data (Jöreskog, 2005). In addition to these fit statistics, we have also provided results from the Sobel (1982) tests for the best-fitting structural model to gain further confidence in our final model.

\section{Results}

Our confirmatory factor analyses (Note 1) combined with Cronbach's (1951) internal consistency reliability tests indicate overall acceptable levels of fit for our study variables. Specifically, the three items used to measure organizational distributive justice load well onto the latent construct (Factor $1=0.89$, Factor $2=0.93$, Factor $3=0.88$ ) and show good levels of internal consistency reliability (Cronbach alpha $=0.89$ ). LMX, further, shows overall good levels of fit to the data $(\chi 2=2.84, \mathrm{df}=2, \chi 2 / \mathrm{df}=1.42, \mathrm{SRMR}=0.01, \mathrm{RMSEA}=0.03, \mathrm{CFI}=1.00$, $\mathrm{GFI}=0.99, \mathrm{ECVI}=0.03$ ), good factor loadings (Factor $1=0.89$, Factor $2=0.85$, Factor $3=0.86$, Factor 4=0.83), and good internal consistency reliability (Cronbach alpha $=0.86$ ). Our TMX items load, overall, satisfactorily onto their latent construct (Factor $1=0.67$, Factor $2=0.91$, Factor 3=0.79), and indicate overall good internal consistency reliability (Cronbach alpha $=0.75$ ). Our customer orientation items load well onto their latent construct (Factor $1=0.77$, Factor $2=0.94$, Factor $3=0.79$ ) and also show good internal consistency reliability (Cronbach alpha $=0.82)$.

In addition to the factor analyses, we also perform measurement independence tests among all our study variables to determine their empirical distinctiveness. Specifically, the one-factor model of organizational distributive justice and $\operatorname{LMX}(\chi 2=542.73, \mathrm{df}=14$, $\chi 2 / \mathrm{df}=38.77, \mathrm{SRMR}=0.18, \mathrm{RMSEA}=0.24, \mathrm{CFI}=0.88, \mathrm{GFI}=0.63, \mathrm{ECVI}=0.87$ ) indicates an overall bad fit to the data, especially when compared to the good-fitting two-factor model $(\chi 2=43.56, \quad \mathrm{df}=13, \quad \chi 2 / \mathrm{df}=3.35, \quad \mathrm{SRMR}=0.05, \quad \mathrm{RMSEA}=0.06, \quad$ CFI $=0.99, \quad$ GFI $=0.94$, ECVI=0.11). Further, these two models are also statistically distinct from each other (SB $\chi^{2}$ difference $=231.17, \mathrm{df}=1, \mathrm{p}<0.001)$. Similarly, the two-factor model of organizational distributive justice and TMX $(\chi 2=17.05, \mathrm{df}=8, \chi 2 / \mathrm{df}=2.13, \mathrm{SRMR}=0.03, \mathrm{RMSEA}=0.04$, $\mathrm{CFI}=1.00, \mathrm{GFI}=0.98, \mathrm{ECVI}=0.07)$ fits the data better than the one-factor model $(\chi 2=363.02$, $\mathrm{df}=9, \chi 2 / \mathrm{df}=40.34, \mathrm{SRMR}=0.18, \mathrm{RMSEA}=0.25, \mathrm{CFI}=0.87, \mathrm{GFI}=0.73, \mathrm{ECVI}=0.59)$ does, and both models are furthermore statistically distinct from each other (SB $\chi 2$ difference $=435.75$, $\mathrm{df}=1, \mathrm{p}<0.001$ ). We found similar results for our organizational distributive justice and customer orientation tests. Specifically, the overall good-fitting two-factor model $(\chi 2=15.77$, $\mathrm{df}=8, \quad \chi 2 / \mathrm{df}=1.97, \quad \mathrm{SRMR}=0.03, \quad \mathrm{RMSEA}=0.04, \quad \mathrm{CFI}=1.00, \quad \mathrm{GFI}=0.98, \quad \mathrm{ECVI}=0.06)$ is statistically distinct $(\mathrm{SB} \chi 2$ difference $=777.72, \mathrm{df}=1, \mathrm{p}<0.001$ ) from the bad-fitting one-factor model $\left(\chi 2=477.65, \mathrm{df}=9, \chi^{2} / \mathrm{df}=53.07, \mathrm{SRMR}=0.19, \mathrm{RMSEA}=0.28, \mathrm{CFI}=0.84, \mathrm{GFI}=0.69\right.$, $\mathrm{ECVI}=0.76$ ). LMX and TMX tested for their statistical independence are also distinct 


\section{Macrothink

concepts, given that the overall good-fitting two-factor model $(\chi 2=41.89, \mathrm{df}=13, \chi 2 / \mathrm{df}=3.22$, $\mathrm{SRMR}=0.04, \mathrm{RMSEA}=0.06, \mathrm{CFI}=0.99, \mathrm{GFI}=0.95, \mathrm{ECVI}=0.11)$ is significantly different $(\mathrm{SB}$ $\chi 2$ difference $=1,761.85, \mathrm{df}=1, \mathrm{p}<0.001)$ from the one-factor model $(\chi 2=194.37, \mathrm{df}=14$, $\left.\chi^{2} / \mathrm{df}=13.88, \quad \mathrm{SRMR}=0.09, \quad \mathrm{RMSEA}=0.14, \quad \mathrm{CFI}=0.96, \quad \mathrm{GFI}=0.81, \quad \mathrm{ECVI}=0.34\right) . \quad$ Our independence tests for the constructs LMX and customer orientation also indicate that the two-factor model $(\chi 2=41.89, \mathrm{df}=13, \chi 2 / \mathrm{df}=3.22, \mathrm{SRMR}=0.05, \mathrm{RMSEA}=0.06, \mathrm{CFI}=0.99$, $\mathrm{GFI}=0.95, \mathrm{ECVI}=0.11$ ) has an overall acceptable fit to the data, whereas the one-factor model has an overall weak fit to the data $(\chi 2=362.02, \mathrm{df}=14, \chi 2 / \mathrm{df}=25.86, \quad \mathrm{SRMR}=0.13$, $\mathrm{RMSEA}=0.19, \mathrm{CFI}=0.92, \mathrm{GFI}=0.72, \mathrm{ECVI}=0.59$ ). Both models are, further, statistically different from each other ( $\mathrm{SB} \chi^{2}$ difference $=451.72, \mathrm{df}=1, \mathrm{p}<0.001$ ). Our last independence test considers the two constructs TMX and customer orientation. The two-factor model for TMX and customer orientation indicates a good fit to the data $(\chi 2=5.97, \mathrm{df}=8, \chi 2 / \mathrm{df}=0.75$, $\mathrm{SRMR}=0.01, \mathrm{RMSEA}=0.00, \mathrm{CFI}=1.00, \mathrm{GFI}=0.99, \mathrm{ECVI}=0.05)$, whereas the statistically different (SB $\chi^{2}$ difference $\left.=-105.65, \mathrm{df}=1, \mathrm{p}<0.001\right)$ one-factor model $(\chi 2=120.48, \mathrm{df}=9$, $\chi 2 / \mathrm{df}=13.39, \mathrm{SRMR}=0.06, \mathrm{RMSEA}=0.14, \mathrm{CFI}=0.97, \mathrm{GFI}=0.88, \mathrm{ECVI}=0.22)$ indicates an overall weak fit to the data. The final test we conducted to determine the statistical robustness of our measurements is the Harman (1976) test. The one-factor model which loads the questionnaire items of all our study variables onto one latent factor $(\chi 2=1,434.07, \mathrm{df}=65$, $\chi 2 / \mathrm{df}=22.06, \mathrm{SRMR}=0.13, \mathrm{RMSEA}=0.18, \mathrm{CFI}=0.89, \mathrm{GFI}=0.58, \mathrm{ECVI}=2.26$ ) shows overall bad fit to the data. The four-factor model, on the other hand, shows an overall good fit to the data $(\chi 2=143.96, \mathrm{df}=59, \chi 2 / \mathrm{df}=2.44, \mathrm{SRMR}=0.05, \mathrm{RMSEA}=0.05, \mathrm{CFI}=0.99, \mathrm{GFI}=0.92$, $\mathrm{ECVI}=0.32)$, and is also statistically different from the one-factor model $\left(\chi^{2}\right.$ difference $=1,173.58, \mathrm{df}=6, \mathrm{p}<0.001)$.

Table 1. Fit statistics for independence and Harman tests

\begin{tabular}{|c|c|c|c|c|c|c|}
\hline Measurement models & & $d f \chi^{2}$ & $\chi^{2} / d f S R M L$ & RMSEA & $\begin{array}{l}\text { RMSEA 90 } \\
\text { (;) }\end{array}$ & I CFI GFI ECVI SB $\chi^{2}[d f]$ \\
\hline $\begin{array}{l}\text { Organizational distributive } \\
\text { leader-member exchange }\end{array}$ & justice & and & & & & \\
\hline Null model & & $214,589.68$ & & & & \\
\hline One-factor model & & 14542.73 & 38.770 .18 & 0.24 & $0.22 ; 0.26$ & $0.880 .63 \quad 0.87$ \\
\hline Two-factor model & & 1343.56 & 3.350 .05 & 0.06 & $0.04 ; 0.08$ & $0.990 .940 .11 \quad 231.17^{* *}$ \\
\hline
\end{tabular}

Organizational distributive justice and team-member

exchange

\begin{tabular}{|c|c|c|c|c|c|c|c|}
\hline Null model & & $2,656.4$ & & & & & \\
\hline One-factor model & 9 & 363.02 & 40.340 .18 & 0.25 & $0.22 ; 0.27$ & $\begin{array}{lll}0.87 & 0.73 & 0.59\end{array}$ & \\
\hline
\end{tabular}

Organizational distributive justice and customer

orientation 


\section{Macrothink}

Human Resource Research

ISSN 1948-5441

2018, Vol. 2, No. 1

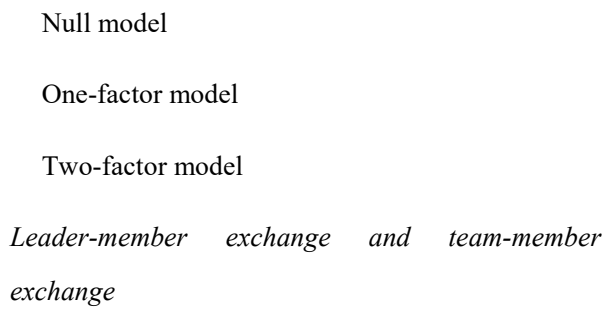

Null model

One-factor model

Two-factor model

Leader-member exchange and team-member exchange

$153,014.29$

$9 \quad 477.65 \quad 53.07 \quad 0.19 \quad 0.28$

$\begin{array}{lllll}8 & 15.77 & 1.97 & 0.03 & 0.04\end{array}$
$0.26 ; 0.30$

$0.01 ; 0.07$
0.840 .690 .76

$1.000 .980 .06 \quad 777.72 * * *[1]$

$$
\begin{aligned}
& \text { Null model } \\
& \text { One-factor model } \\
& \text { Two-factor model }
\end{aligned}
$$

\begin{tabular}{|c|c|c|c|}
\hline 14194.37 & 13.880 .09 & 0.14 & $0.12 ; 0.16$ \\
\hline 1341.89 & $3.22 \quad 0.04$ & 0.06 & $0.04 ; 0.08$ \\
\hline
\end{tabular}

\section{$214,793.22$}

0.960 .810 .34

$0.990 .950 .11 \quad 1,761.85^{* * *}$

[1]

Leader-member exchange and customer orientation

$$
\begin{aligned}
& \text { Null model } \\
& \text { One-factor model } \\
& \text { Two-factor model }
\end{aligned}
$$

Team-member exchange and customer orientation

$$
\begin{aligned}
& \text { Null model } \\
& \text { One-factor model } \\
& \text { Two-factor model }
\end{aligned}
$$

Harman test

$$
\begin{aligned}
& \text { Null model } \\
& \text { One-factor model } \\
& \text { Four-factor model }
\end{aligned}
$$

\section{$214,519.74$}

$$
\begin{array}{lllll}
14362.02 & 25.86 & 0.13 & 0.19 & 0.18 ; 0.21 \\
1341.89 & 3.22 & 0.05 & 0.06 & 0.04 ; 0.08
\end{array}
$$

$\begin{array}{lll}0.92 & 0.720 .59\end{array}$

$0.990 .950 .11 \quad 451.72 * * *[1]$

\begin{abstract}
$153,414.06$
$\begin{array}{lllll}9 & 120.48 & 13.39 & 0.06 & 0.14\end{array}$

$\begin{array}{lllll}8 & 5.97 & 0.75 & 0.01 & 0.00\end{array}$

$0.12 ; 0.16$

$0.00 ; 0.04$

0.970 .880 .22

$1.000 .990 .05-105.65^{* * *}$
\end{abstract}

$[1]^{\mathrm{a}}$

Note: $* * * \mathrm{p}<0.001, * * \mathrm{p}<0.01,{ }^{*} \mathrm{p}<0.05 .{ }^{\text {a }}$ Please note the negative SB $\chi 2$ value and Satorra $\&$ Bentler's (2010) explanation for rarely occurring negative values in their recommended analysis.

\subsection{Descriptive Statistics}

Table 1 reports the results of our correlation analyses for all study variables. The correlation between organizational distributive justice $(\mathrm{r}=0.39, \mathrm{p}<0.001)$ and $\operatorname{LMX}(\mathrm{r}=0.48, \mathrm{p}<0.001)$ and customer orientation is positive, as predicted by Hypotheses 1 and 2, respectively. Further, organizational distributive justice is positively correlated with $\operatorname{LMX}(\mathrm{r}=0.41, \mathrm{p}<0.001)$ and TMX ( $\mathrm{r}=0.34, \mathrm{p}<0.001)$. LMX also correlates positively with $\mathrm{TMX}(\mathrm{r}=0.56, \mathrm{p}<0.001)$, and TMX with customer orientation $(\mathrm{r}=0.62, \mathrm{p}<0.001)$. 
Our control variables also correlate with some of our study variables. To be precise, age correlates positively with organizational tenure $(\mathrm{r}=0.83, \mathrm{p}<0.001)$, organizational distributive justice $(r=0.15, p<0.001)$, TMX $(r=0.25, p<0.001)$, customer orientation $(r=0.32, p<0.001)$, and negatively with the educational level of our respondents $(r=-0.32, p<0.001)$. Gender correlates negatively with educational level $(\mathrm{r}=-0.11, \mathrm{p}<0.01)$, and a similar relationship was found between organizational tenure and educational level $(-0.33, p<0.001)$. Organizational tenure, furthermore, correlates positively with organizational distributive justice $(r=0.13$, $\mathrm{p}<0.01)$, TMX $(\mathrm{r}=0.29, \mathrm{p}<0.001)$, and customer orientation $(\mathrm{r}=0.36, \mathrm{p}<0.001)$. Educational level correlates negatively with $\operatorname{TMX}(-0.15, \mathrm{p}<0.001)$, and customer orientation $(\mathrm{r}=-0.20$, $\mathrm{p}<0.001)$. Table 2 presents the descriptive statistics and correlations.

Table 2. Descriptive statistics and correlations

\begin{tabular}{|c|c|c|c|c|c|c|c|c|c|c|}
\hline & Study variable & Mean & $S D$ & 1 & 2 & 3 & 4 & 5 & 6 & 7 \\
\hline 1 & Age & 2.79 & 1.10 & & & & & & & \\
\hline 2 & Gender & 1.17 & 0.51 & -0.06 & & & & & & \\
\hline 3 & Organizational tenure & 3.90 & 1.89 & $0.83 * * *$ & -0.02 & & & & & \\
\hline 4 & Educational level & 5.59 & 1.06 & $-0.32 * * *$ & $-0.11 * *$ & $-0.33 * * *$ & & & & \\
\hline 5 & Organizational distributive justice & 3.08 & 1.38 & $0.15 * * *$ & -0.08 & $0.13 * *$ & -0.04 & & & \\
\hline 6 & Leader-member exchange & 4.27 & 0.93 & 0.05 & -0.05 & 0.05 & -0.04 & $0.41 * * *$ & & \\
\hline 7 & Team-member exchange & 3.98 & 1.01 & $0.25 * * *$ & -0.02 & $0.29 * * *$ & $-0.15^{* * *}$ & $0.34 * * *$ & $0.56^{* * *}$ & \\
\hline 8 & Customer orientation & 3.69 & 1.14 & $0.32 * * *$ & 0.00 & $0.36^{* * *}$ & $-0.20 * * *$ & $0.39 * * *$ & $0.48^{* * *}$ & $0.62 * * *$ \\
\hline
\end{tabular}

Note: $\mathrm{N}=658 ; * * * \mathrm{p}<0.001, * * \mathrm{p}<0.01,{ }^{*} \mathrm{p}<0.05$; Age (only one group to be indicated by respondent): age group $1=20-30$ years, age group $2=31-40$ years, age group $3=41-50$ years, age group 4=51 years and above; Gender (only one box to be indicated by respondent): male $=1$, female $=2$, Organizational tenure (only one group to be indicated by respondent): group $1=$ less than 1 year, group 2=1-3 years, group 3=4-10 years, group 4=11-20 years, group 5=21-30 years, group $6=30$ years or more; Education level (only one group to be indicated by respondent): group $1=$ Matric, group $2=$ Intermediate, group $3=\mathrm{O}$-Level, group 4=A-Level, group 5=Graduate, group 6=Post graduate, group 7=Ph.D., group 8=Other.

\subsection{Structural Models}

Our approach to testing the structural models composes of three steps. Firstly, we present a model which tests for full mediation between the independent variables of organizational distributive justice and LMX, the mediator TMX, and the dependent variable customer orientation. This model shows overall acceptable levels of fit $(\chi 2=309.46, \mathrm{df}=97, \chi 2 / \mathrm{df}=3.19$, $\mathrm{SRMR}=0.05, \mathrm{RMSEA}=0.06, \mathrm{CFI}=0.98, \mathrm{GFI}=0.95, \mathrm{ECVI}=0.64)$, and both organizational distributive justice (beta $=0.13, \mathrm{p}<0.01$ ) and LMX (beta $=0.63, \mathrm{p}<0.001)$ are related significantly to the mediator TMX, which in turn is related to the dependent variable customer orientation ( $\mathrm{beta}=0.74, \mathrm{p}<0.001$ ). Organizational tenure is the only control variable 
which is significantly related to TMX (beta $=0.40, \mathrm{p}<0.01$ ) in this model. The other control variables age (beta $=-0.15, \mathrm{p}>0.05$ ), gender (beta $=0.01, \mathrm{p}>0.05$ ), and educational level (beta $=-0.03, \mathrm{p}>0.05$ ) are not related to either TMX or to customer orientation (age: beta $=-0.02, p>0.05$; gender: beta $=0.01, \mathrm{p}>0.05$; educational level: beta $=-0.05, \mathrm{p}>0.05$ ). The path between organizational tenure and customer orientation is also non-significant (beta $=0.17, \mathrm{p}>0.05$ ) in this model.

Our second model, the partially mediated model, fits the data slightly better than the full mediation model $(\chi 2=294.20, \mathrm{df}=95, \chi 2 / \mathrm{df}=3.10, \mathrm{SRMR}=0.05, \mathrm{RMSEA}=0.06, \mathrm{CFI}=0.98$, $\mathrm{GFI}=0.95$, ECVI $=0.62$ ), and indicates that the independent variables organizational distributive justice (beta $=0.10, \mathrm{p}<0.05$ ) and LMX (beta $=0.63, \mathrm{p}<0.001$ ) are related to the mediator TMX and that, simultaneously, organizational distributive justice is related to the independent variable customer orientation (beta $=0.13, \mathrm{p}<0.01$ ). The mediator TMX is also related significantly to the dependent variable customer orientation (beta $=0.63, \mathrm{p}<0.001$ ) in this model. Further, organizational tenure is related significantly to TMX (beta $=0.39, p<0.01$ ) and to customer orientation (beta $=0.28, \mathrm{p}<0.05$ ). The direct paths between LMX (beta $=0.05$, $\mathrm{p}>0.05$ ), age (beta $=-0.11, \mathrm{p}>0.05$ ), gender (beta $=0.02, \mathrm{p}>0.05$ ), and educational level (beta $=-0.05, \mathrm{p}>0.05$ ), and the dependent variable customer orientation are non-significant. The control variables age ( $b e t a=-0.13, p>0.05$ ), gender ( $b e t a=0.01, p>0.05$ ), and educational level (beta $=-0.03, \mathrm{p}>0.05$ ) are not related significantly to the mediator TMX.

Our third and final structural model tests only the direct relationships between organizational distributive justice (beta=0.19, $\mathrm{p}<0.001$ ), LMX (beta=0.44, $\mathrm{p}<0.001$ ), and customer orientation, and shows overall the weakest fit to the data of all three models $(\chi 2=203.47$, $\mathrm{df}=60, \quad \chi 2 / \mathrm{df}=3.39, \quad \mathrm{SRMR}=0.05, \quad \mathrm{RMSEA}=0.06, \quad \mathrm{CFI}=0.98, \quad \mathrm{GFI}=0.96, \quad \mathrm{ECVI}=0.45)$. Organizational tenure (beta $=0.52, \mathrm{p}<0.001$ ) also relates significantly to customer orientation in this model, but the other control variables age (beta $=-0.19, p>0.05$ ), gender (beta $=0.02$, $\mathrm{p}>0.05$ ), and educational level (beta $=-0.07, \mathrm{p}>0.05$ ) show no significant relationship with the dependent variable.

In addition to these structural tests, we perform $\chi^{2}$ difference tests to determine whether the three models are significantly different from each other. The best-fitting partially mediated model, in fact, is different from the fully mediated model $(\chi 2$ difference $=15.26, \mathrm{df}=2$, $\mathrm{p}<0.001$ ), and from the non-mediated model ( $\chi 2$ difference $=90.73, \mathrm{df}=35, \mathrm{p}<0.001)$. The fully mediated model is also different from the non-mediated model ( $\chi 2$ difference $=105.99$, $\mathrm{df}=37, \mathrm{p}<0.001)$. We perform Sobel (1982) tests on the best-fitting partially mediated model to gain further confidence in the structural relationships. This additional testing indicates that TMX mediates the relationships between organizational distributive justice and customer orientation (Sobel=2.08, p<0.05), between LMX and customer orientation (Sobel=6.43, $\mathrm{p}<0.001$ ), and between organizational tenure and customer orientation (Sobel $=2.54, \mathrm{p}<0.05$ ). Hypotheses 3 and 4 are supported by the data. Figure 2 depicts all significant relationships from this best-fitting partially mediated structural model. Non-significant paths, however, are not displayed due to graphical constraints. 


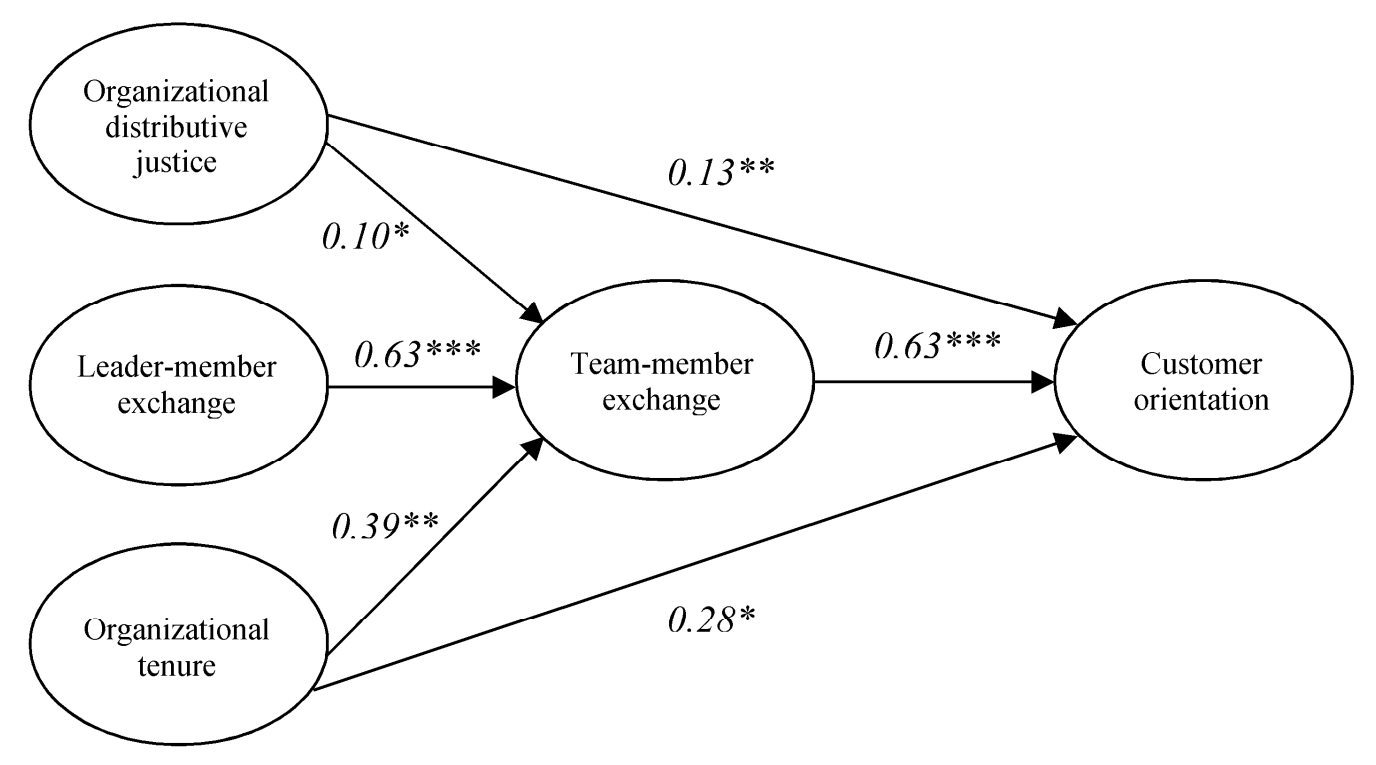

Figure 2. The best-fitting partially mediated model

Note: $* * * p<0.001, * * p<0.01, * p<0.05$.

\section{Discussion}

Overall, our results extend the existing work that looks at the links between organizational distributive justice, LMX, TMX, and customer orientation. Specifically, the results of our study indicate a best-fitting partially mediated model (see Figure 2) among the chosen study variables. In total, there are four key findings. The first finding is that organizational distributive justice has a positive relationship with customer orientation. The second finding is that LMX has a positive relationship with customer orientation. The third finding is that TMX partially mediates the relationship between organizational distributive justice and customer orientation. The fourth finding is that TMX mediates the relationship between LMX and customer orientation. To further elaborate and reflect on these findings, the following discussion reviews them in greater detail and against the current literature.

Firstly, our study shows that organizational distributive justice is positively related to customer orientation. We can, based on this, argue that distributive justice is a crucial mechanism which can create engagement through organizational policies, practices, and procedures which are intended to support and reward behaviors focused on service excellence (Lytle et al., 1998). Our work adds to that of Chou and Lopez-Rodriguez (2013) who argue that service employees are likely to engage in service-related discretionary behaviors as an exchange for fair treatment received by the organization, and that service employee' perceptions of fair treatment are expected to have a positive impact on their SOCBs, such as customer orientation.

Secondly, our study indicates that LMX is positively related to customer orientation. This is an important finding because it demonstrates the significance of leaders and of leadership behaviors for creating customer orientation (Menguc \& Auh, 2008; Martin \& Bush, 2003). 


\section{Macrothink}

More specifically, our study adds to the work of Paparoidamis and Guenzi (2009) and Farrell and Oczkowski (2012) who also found a significant LMX-customer orientation relationship.

Thirdly, we found that TMX partially mediates the relationship between organizational distributive justice and customer orientation. This means that social interactions in the workplace can be affected by the perceived levels of fairness and that the fairer employees perceive the organization to be, the more positive their relationships with their co-workers are. Our findings are in accordance with prior research which has explored the positive relationship between justice perceptions and TMX (e.g. Murphy, Wayne, Liden \& Erdogan, 2003). Such positive relationships can lead to desirable organizational outcomes, such as excellent customer support through customer orientation.

Fourthly, our study shows that TMX mediates the relationship between LMX and customer orientation. We provide additional support for the idea that leaders and leadership styles are important for influencing TMX, as previously discussed in the literature (Menguc \& Auh, 2008; Martin \& Bush, 2003), within the Pakistani banking context. Psychological and socio-emotional support between colleagues can facilitate organizational identification with positive effects on employee in-role and organizational citizenship behavior (Kwan et al., 2015; Liu et al., 2011) and, thus, positively affect behaviors such as customer orientation. The SOCB literature (Chou \& Lopez-Rodriguez, 2013) discusses how such behaviors can lead to increased employee loyalty and participation and overall higher-quality service delivery (Bettencourt et al., 2001). Our study adds to this body of research and suggests that co-worker interactions in the workplace are crucial in creating customer loyalty and satisfaction (Lytle \& Timmerman, 2006; Homburg et al., 2002; Lytle et al., 1998). The mediating effects of TMX between organizational distributive justice and customer orientation and LMX and customer orientation may be explained as TMX alone does not account significantly enough for customer orientation. In practical terms, good co-worker interactions and relationships on their own may not be enough to create organizational identification, employee commitment, and drive individual employees to exhibit desirable organizational citizenship behaviors, such as customer-oriented behaviors. Indeed, other factors such as psychological ownership for the organization and the work environment have also been found to affect citizenship behaviors (O'Driscoll, Pierce \& Coghlan, 2006). The results indicate that organizational distributive justice and LMX are expected to encourage employees to more positively interact with co-workers, and once individuals develop effective team relationships, they become more likely to behaviorally support SOCBs such as customer orientation.

Our results also indicate that organizational tenure plays a significant role in the presented model as it relates positively to TMX and customer orientation. This is in line with Fuchs and Edwards (2012) and Riketta (2005) who suggest that tenure is positively related to organizational identification through a gradual convergence of values and goals between employees and the organization. This, importantly, is a rather interesting finding in itself that ought to be further explored, as there is the possibility that organizational tenure may be a direct antecedent of TMX and LMX, rather than LMX being an antecedent of TMX. 


\section{Conclusions}

Beyond the academic significance of these findings, important implications for managers, leaders, and entire organizations in enabling positive organizational outcomes such as customer orientation, can be drawn. The discovery of organizational distributive justice, LMX and TMX as key predictors of SOCBs, such as customer orientation, signifies that managers, leaders, and also co-workers all play a key role in affecting employee behaviors and enabling positive organizational outcomes. This means that service organizations wishing to create a culture of service excellence (Lytle et al., 1998; Lytle \& Timmerman, 2006) need to place emphasis on three organizational levels. On a leadership level, it is important to have appropriate leadership that positively affects individuals and teams at work in relation to the desired outcome (Paparoidamis \& Guenzi, 2009; Farrell \& Oczkowski, 2012). On a managerial level, the notion of organizational distributive justice as a key predictor of customer orientation signifies the importance of managers in creating positive employee perceptions of fair treatment at work, especially in terms of distributions and rewards. On a co-worker level, our study shows the importance of team dynamics in creating SOCBs and customer orientation.

\subsection{Limitations}

Further to the above highlighted implications, our study comes with some limitations. For example, the exclusive use of self-reported measures, especially for our customer orientation scale, can be seen as one limitation of the study. A more accurate measure would have been to ask customers about their perceptions of customer orientation, which is what we encourage other scholars to do in future research. Moreover, this study focuses on a sample of middle managers and not employees and more senior managers of the organization which would have provided a more holistic view on the tested variables. Further, the context of our investigation is a single organization operating in a specific industry. Testing these relationships in a different context would enhance the overall rigor of the study and the level of generalizability of the findings. The nature of our data is cross-sectional. Longitudinal data which allows for testing across different times would improve the reliability of our data and we henceforth encourage scholars to test the proposed model using a longitudinal research design in the future.

\subsection{Future Research}

Despite these limitations, there are a number of future research avenues arising from our study. Firstly, although current literature discusses the role of leadership in affecting organizational citizenship behaviors, more research is needed in exploring particular leadership styles that may be applied to a service-oriented organizational culture. Secondly, there is more work needed in exploring how employees define fair treatment at work in a services context and how managers can affect their perceptions of this. Thirdly, although we found that TMX affects customer orientation positively, more research is needed in untangling team dynamics and their power over employee behaviors associated with customer orientation as an outcome variable. More organizational behavior and management studies in the Pakistani context can widen both scholars' and practitioners' views on emerging economies, such as Brazil, Russia, India and China, which fall outside the more frequently researched countries. 


\section{Mll Macrothink}

\section{References}

Appelbaum, S., Al Asmar, J., Chehayeb, R,. Konidas, N., Maksymiw-Duszara, V., \& Duminica, I. (2003). Organizational citizenship: A case study of MedLink Ltd. Team Performance Management: An International Journal, 9(5/6), 136-154. https://doi.org/10.1108/13527590310493882

Auh, S., Menguc, B., \& Jung, Y. S. (2014). Unpacking the relationship between empowering leadership and service-oriented citizenship behaviors: A multilevel approach. Journal of the Academy of Marketing Science, 42(5), 558-579. https://doi.org/10.1007/s11747-014-0370-0

Balogun, J., \& Johnson, G. (2004). Organizational restructuring and middle manager sense making. Academy of Management Journal, 47(4), 523-549. https://doi.org/10.2307/20159600

Baron, R. M., \& Kenny, D. A. (1986). The moderator-mediator variable distinction in social psychological research: Conceptual, strategic, and statistical considerations. Journal of Personality and Social Psychology, 51(6), 1173-1182. https://doi.org/10.1037/0022-3514.51. 6.1173

Bettencourt, L. A., Gwinner, K. P., \& Meuter, M. L. (2001). A comparison of attitude, personality, and knowledge predictors of service-oriented organizational citizenship behaviors. Journal of Applied Psychology, 86(1), 29-41. https://doi.org/10.1037/0021-9010. 86.1.29

Biswas, S., Varma, A., \& Ramaswami, A. (2013). Linking distributive and procedural justice to employee engagement through social exchange: A field study in India. The International Journal of Human Resource Management, 24(8), 1580-1587. https://doi.org/10.1080/0958 5192.2012.725072

Bollen, K. A. (1989). Structural equations with latent variables. New York: John Wiley.

Bowen, D. E., \& Schneider, B. (2014). A service climate synthesis and future research agenda. Journal of Service Research, 17(1), 5-22. https://doi.org/10.1177/1094670513491633 Brunetto, Y., Farr-Wharton, R., \& Shacklock, K. (2010). The impact of supervisor-subordinate relationships on morale: Implications for public and private sector nurses' commitment. Human Resource Management Journal, 20(2), 206-225. https://doi.org/10.1111/j.1748-8583.2009.00117.x

Byrne, Z. S., \& Hochwarter, W. A. (2008). Perceived organizational support and performance: Relationships across levels of organizational cynicism. Journal of Managerial Psychology, 23(1), 54-72. https://doi.org/10.1108/02683940810849666

Cardona, P., Lawrence, B. S., \& Bentler, P. M. (2004). The influence of social and work exchange relationships on organizational citizenship behavior. Group \& Organization Management, 29(2), 219-247. https://doi.org/10.1177/1059601103257401

Carter, M. Z., Mossholder, K. W., Field, H. S., \& Armenakis, A. A. (2014). Transformational leadership, interactional justice, and organizational citizenship behavior: The effects of racial and gender dissimilarity between supervisors and subordinates. Group \& Organization Management, 39(6), 691-719. https://doi.org/10.1177/1059601114551605 


\section{MInstitute Macrothink $^{\text {Int }}$}

Castro, C. B., Armario, E. M., \& Ruiz, D. M. (2004). The influence of employee organizational citizenship behavior on customer loyalty. International Journal of Service Industry Management, 15(1), 27-53. https://doi.org/10.1108/09564230410523321

Chiaburu, D. S., Lorinkova, N. M., \& Van Dyne, L. (2013). Employees' social context and change-oriented citizenship: A meta-analysis of leader, coworker, and organizational influences. Group \& Organization Management, 38(3), 291-333. https://doi.org/10.1177/105 9601113476736

Chou, S. Y., \& Lopez-Rodriguez, E. (2013). An empirical examination of service-oriented organizational citizenship behavior: The roles of justice perceptions and manifest needs. Managing Service Quality, 23(6), 474-494. https://doi.org/10.1108/MSQ-02-2013-0019

Colquitt, J. A., Conlon, D. E., Wesson, M. J., Porter, C., \& Ng, K. Y. (2001). Justice at the millennium: A meta-analytic review of 25 years of organizational justice research. Journal of Applied Psychology, 86(3), 425-445. https://doi.org/10.1037/0021-9010.86.3.425

Cronbach, L. J. (1951). Coefficient alpha and the internal structure of tests. Psychometrika, 16(3), 297-334. https://doi.org/10.1007/BF02310555

Cross, M. E., Brashear, T. G., Rigdon, E. E., \& Bellenger, D. N. (2007). Customer orientation and salesperson performance. European Journal of Marketing, 41(7/8), 821-835. https://doi.org/10.1108/03090560710752410

DeConinck, J. B, \& Stilwell, C. D. (2004). Incorporating organizational justice, role states, pay satisfaction in a model of turnover intentions. Journal of Business Research, 57(3), 225-231. https://doi.org/10.1016/S0148-2963(02)00289-8

DeVellis, R. F. (2003). Scale development: Theory and applications. Thousand Oaks: Sage Publications.

Dopson, S., Risk, A., \& Stewart, R. (1992). The changing role of the middle manager in the United Kingdom. International Studies of Management \& Organization, 22(1), 40-49. https://doi.org/10.1080/00208825.1992.11656574

Farrell, M. A., \& Oczkowski, E. (2012). Organizational identification and leader member exchange influences on customer orientation and organizational citizenship behaviors. Journal of Strategic Marketing, 20(4), 365-377. https://doi.org/10.1080/0965254X. 2011.643917

Fuchs, S., \& Edwards, M. R. (2012). Predicting pro-change behavior: the role of perceived organizational justice and organizational identification. Human Resource Management Journal, 22(1), 39-59. https://doi.org/10.1111/j.1748-8583.2011.00167.x

Fuchs, S., \& Prouska, R. (2014). Creating positive employee change evaluation: The role of different levels of organizational support and change participation. Journal of Change Management, 14(3), 361-383. https://doi.org/10.1080/14697017.2014.885460

Gelens, J., Hofmans, J., Dries, N., \& Pepermans, R. (2014). Talent management and organizational justice: Employee reactions to high potential identification. Human Resource Management Journal, 24(2), 159-175. https://doi.org/10.1111/1748-8583.12029

González, J. V., \& Garazo, T. G. (2006). Structural relationships between organizational service orientation, contact employee job satisfaction and citizenship behavior. International 
Journal of Service Industry Management, 17(1), 23-50. https://doi.org/10.1108/095642 30610651561

Halstead, D., Jones, M. A., Lesseig, V. P., \& Smythe, T. I. (2008). The customer orientation of financial advisers. Journal of Financial Services Marketing, 13(3), 183-192. https://doi.org/10.1007/978-3-319-30886-9_12

Harman, H. H. (1976). Modern factor analysis. Chicago: The University of Chicago Press.

Harris, L. C., \& Ogbanna, E. (2001). Leadership style and market orientation: An empirical study. European Journal of Marketing, 35(5/6), 744-764. https://doi.org/10.1108/03090560 110388196

Hesselgreaves, H., \& Scholarios, D. (2014). Leader-member exchange and strain: A study of job demands and role status. Human Resource Management Journal, 24(4), 459-478. https://doi.org/10.1111/1748-8583.12042

Homburg, C., Hoyer, W., \& Fassnacht, M. (2002). Service orientation of a retailer's business strategy: Dimensions, antecedents, and performance outcomes. Journal of Marketing, 66(4), 86-101. https://doi.org/10.1509/jmkg.66.4.86.18511

Hornung, S., Glaser, J., \& Rouseau, D. M. (2010). Interdependence as an i(-)deal: Enhancing job autonomy and distributive justice via individual negotiation. German Journal of Human Resource Management, 24(2), 108-129. https://doi.org/10.1177/239700221002400202

House, R. J., Hanges, P. J., Javidan, M., Dorfman, P. W., \& Gupta, V. (2004). Culture, leadership, and organizations: The GLOBE study of 62 societies. Thousand Oaks: Sage Publications.

Hu, L., \& Bentler, P. M. (1999). Cutoff criteria for fit indexes in covariance structure analysis: Conventional criteria versus new alternatives. Structural Equation Modeling, 6(1), 1-55. https://doi.org/10.1080/10705519909540118

Huy, Q. (2011). How middle managers' group-focus emotions and social identities influence top-down implementation of a new strategy. Strategic Management Journal, 32(13).

Ilies, R., Nahrgang, J. D., \& Morgeson, F. P. (2007). Leader-member exchange and citizenship behaviors: A meta-analysis. Journal of Applied Psychology, 92(1), 269-277. https://doi.org/10.1037/0021-9010.92.1.269

Jain, A. K., Malhotra, N. K., \& Guan, C. (2012). Positive and negative affectivity as mediators of volunteerism and service-oriented citizenship behavior and customer loyalty. Psychology \& Marketing, 29(12), 1004-1017. https://doi.org/10.1002/mar.20582

Jiao, C., Richards, D. A., \& Hackett, R. D. (2013). Organizational citizenship behavior and role breadth: A meta-analytic and cross-cultural analysis. Human Resource Management, 52(5), 697-714. https://doi.org/10.1002/hrm.21555

Jöreskog, K. G. (2005). Structural equation modeling with ordinal variables using LISREL. Retrieved from www.ssicentral.com/lisrel/techdocs/ordinal.pdf

Jormanainen, I., \& Koveshnikov, A. (2012). International activities of emerging market firms: A critical assessment of research in top international management journals. Management International Review, 52(5), 691-725. https://doi.org/10.1007/s11575-011-0115-y 
Kahrobaei, S., \& Mortazavi, S. (2016). How leader-member exchange can uplift team's energy to increase creative work involvement. Team Performance Management: An International Journal, 22(1/2), 75-91. https://doi.org/10.1108/TPM-06-2015-0029

Kelloway, E. K. (1998). Using LISREL for structural equation modeling: A researcher's guide. Thousand Oaks: Sage Publications.

Kuvaas, B., \& Dysvik, A. (2010). Exploring alternative relationships between perceived investment in employee development, perceived supervisor support and employee outcomes. Human Resource Management Journal, 20(2), 138-156. https://doi.org/10.1111/j.1748-8583. 2009.00120.x

Kwan, H. K., Yim, F. H., \& Zhou, X. (2015). Effects of mentoring on customer orientation: The moderating role of gender. Asia Pacific Journal of Human Resources, 53(1), 124-140. Lanjananda, P., \& Patterson, P. G. (2009). Determinants of customer-oriented behavior in a health care context. Journal of Service Management, 20(1), 5-32.

Liu, Y., Loi, R., \& Lam, L. W. (2011). Linking organizational identification and employee performance in teams: The moderating role of team-member exchange. The International Journal of Human Resource Management, 22(15), 3187-3201. https://doi.org/10.1080 /09585192.2011.560875

Long, J. S. (1983). Confirmatory factor analysis: A preface to LISREL. Sage university paper series on quantitative applications in the social sciences, Newbury Park: Sage Publications. https://doi.org/10.4135/9781412983778

Lytle, R. S., Hom, P. W., \& Mokwa, M. P. (1998). SERV*OR: A managerial measure of organizational service-orientation. Journal of Retailing, 74(4), 455-489. https://doi.org/ 10.1016/S0022-4359(99)80104-3

Lytle, R. S., \& Timmerman, J. E. (2006). Service orientation and performance: An organizational perspective. Journal of Services Marketing, 20(2), 136-147. https://doi.org/10.1108/08876040610657066

Maas, P., \& Graf, A. (2004). Leadership by customers? New roles of service companies' customers. German Journal of Human Resource Management, 18(3), 329-345. https://doi.org/10.1007/978-3-319-11761-4_20

MacKenzie, S. B., Podsakoff, P. M., \& Rich, G. A. (2001). Transformational and transactional leadership and salesperson performance. Journal of the Academy of Marketing Science, 29(2), 115-134. https://doi.org/10.1177/03079459994506

Mahajan, A., \& Benson, P. (2013). Organizational justice climate, social capital and firm performance. Journal of Management Development, 32(7), 721-736. https://doi.org/10.1108 /JMD-12-2010-0091

Martin, C. A., \& Bush, A. J. (2003). The potential influence of organizational and personal variables in customer-oriented selling. Journal of Business and Industrial Marketing, 18(2), 114-132. https://doi.org/10.1108/08858620310463051

Menguc, B., \& Auh, S. (2008). Conflict, leadership, and market orientation. International Journal of Research in Marketing, 25(1), 34-45. https://doi.org/10.1016/j.ijresmar. 2007.08.001 
Murphy, S. M., Wayne, S. J., Liden, R. C., \& Erdogan, B. (2003). Understanding social loafing: The role of justice perceptions and exchange relationships. Human Relations, 56(1), 61-84. https://doi.org/10.1177/0018726703056001450

O'Driscoll, M. P., Pierce, J. L., \& Coghlan, A. M. (2006). The psychology of ownership: Work environment structure, organizational commitment, and citizenship behaviors. Group \& Organization Management, 31(3), 388-416. https://doi.org/10.1177/1059601104273066

Ohana, M. (2012). Perceived organizational support as mediator of distributive justice and job satisfaction: The moderating role of group commitment. Journal of Applied Business Research, 28(5), 1063-1072. https://doi.org/10.19030/jabr.v28i5.7246

Organ, D. W., Podsakoff, P., \& MacKenzie, S. (2006). Organizational citizenship behavior: Its nature, antecedents, and consequences. Thousand Oaks: Sage Publications.

Paillé, P. (2009). The relationship between support, commitment and intent to leave team. Team Performance Management: An International Journal, 15(1/2), 49-62. https://doi.org/10. 1108/13527590910937711

Paparoidamis, N. G., \& Guenzi, P. (2009). An empirical investigation into the impact of relationship selling and LMX on salespeople's behaviors and sales effectiveness. European Journal of Marketing, 43(7/8), 1053-1075. https://doi.org/10.1108/03090560910961515

Podsakoff, N. P., Whiting, S. W., Podsakoff, P. M., \& Blume, B. D. (2009). Individual and organizational level consequences of organizational citizenship behaviors: A meta-analysis. Journal of Applied Psychology, 94(1), 122-141. https://doi.org/10.1037/a0013079

Psychogios, A., Alexandris, K., \& Onofrei, A. (2008). Addressing individual and organizational factors influencing middle managers synthesizing role in knowledge creation and diffusion. International Journal of Learning \& Intellectual Capital, 5(2), 208-222. https://doi.org/10.1504/IJLIC.2008.020152

Pundt, A., Martins, E., \& Nerdinger, F. W. (2010). Innovative behavior and the reciprocal exchange between employees and organizations. German Journal of Human Resource Management, 24(2), 173-193. https://doi.org/10.1177/239700221002400205

Qayyum, A., Sukirno, A., \& Mahmood, A. (2011). A preliminary investigation of employee motivation in Pakistan's banking sector. Research and Practice in Human Resource Management, 19(1), 38-52.

Rammal, H. G., \& Parker, L. D. (2012). Islamic banking in Pakistan: A history of emergent accountability and regulation. Accounting History, 18(1), 5-29. https://doi.org/10.1177\%2F 1032373212463269

Rhoades, L., \& Eisenberger, R. (2002). Perceived organizational support: A review of the literature. Journal of Applied Psychology, 87(4), 698-714. https://doi.org/10.1037/0021 $-9010.87 .4 .698$

Satorra, A., \& Bentler, P. M. (2010). Ensuring positiveness of the scaled difference chi-square test statistic. Psychometrika, 75(2), 243-248. https://doi.org/10.1007/s1133 6-009-9135-y

Saxe, R., \& Weitz, B. A. (1982). The SOCO scale: A measure of the customer orientation of salespeople. Journal of Marketing Research, 19(3), 343-351. https://doi.org/10.2307/3151568 


\section{Macrothink}

Human Resource Research

ISSN 1948-5441

2018, Vol. 2, No. 1

Seers, A. (1989). Team-member exchange quality: A new construct for role-making research.

Organizational Behavior and Human Decision Processes, 43(1), 118-135. https://doi.org/10.1016/0749-5978(89)90060-5

Seers, A., Petty, M. M., \& Cashman, J. F. (1995). Team-member exchange under team and traditional management: A naturally occurring quasi-experiment. Group \& Organization Management, 20(1), 18-38. https://doi.org/10.1177/1059601195201003

Shetach, A., \& Marcus, O. (2015). Citizenship-behavior, cooperation and job satisfaction of medical and nursing teams in an Israeli hospital. Team Performance Management: An International Journal, 21(3/4), 181-198. https://doi.org/10.1108/TPM-11-2014-0058

Sobel, M. E. (1982). Asymptotic confidence intervals for indirect effects in structural equation models. Sociological Methodology, 13, 290-312. https://doi.org/10.2307/270723

Steffens, N. K., Haslam, S. A., Kerschreiter, R., Schuh, S. C., \& van Dick, R. (2014). Leaders enhance group members' work engagement and reduce their burnout by crafting social identity. German Journal of Human Resource Management, 29(1/2), 173-194. https://doi.org/10.1177/ 239700221402800110

Tangirala, S., Green, S. G., \& Ramanujam, R. (2007). In the shadow of the boss's boss: Effects of supervisors' upward exchange relationships on employees. Journal of Applied Psychology, 92(2), 309-320. https://doi.org/10.1037/0021-9010.92.2.309

Wang, H., Law, K. S., \& Chen, Z. X. (2008). Leader-member exchange, employee performance, and work outcomes: An empirical study in the Chinese context. The International Journal of Human Resource Management, 19(10), 1809-1824. https://doi.org/10.1080/09585190802323926

Weschek, J. S., \& Teichmann, E. (2016). Status matters: The moderating role of perceived newcomer status in leader and coworker influences on challenging organizational citizenship behavior. German Journal of Human Resource Management, 30(3/4), 267-286. https://doi.org/10.1177/2397002216649898

\section{Notes}

Note 1. Please note that LISREL 8.80 (SSI, Scientific Software International, Lincolnwood, IL) does not provide fit statistics for measurement scales that compose of three or less items. For this reason, the factor loadings and Cronbach alphas are commented on to allow the reader more insight into the suitability of our measures.

\section{Copyright Disclaimer}

Copyright for this article is retained by the author(s), with first publication rights granted to the journal.

This is an open-access article distributed under the terms and conditions of the Creative Commons Attribution license (http://creativecommons.org/licenses/by/3.0/). 